\title{
Analysis of contributing factors for synthesizing silicon carbide using Taguchi's approach
}

\author{
Mohd Aizat Hafiz Mohd Sohor ${ }^{1 *}$, Mazli Mustapha ${ }^{1}$, and Othman Mamat ${ }^{1}$ \\ ${ }^{1}$ Mechanical Engineering Department, Universiti Teknologi PETRONAS (UTP), 32610 Seri Iskandar, \\ Perak, Malaysia
}

\begin{abstract}
This study concerns the carbothermal reduction of milled amorphous silicon dioxide $\left(\mathrm{SiO}_{2}\right)$ to produce silicon carbide $(\mathrm{SiC})$ using Taguchi's approach. The L9(34) orthogonal design matrix was selected involving four operation specifications; temperature, mechanical milling time, heating rate and time on amorphous $\mathrm{SiO}_{2}$ under carbothermal reduction. The responses were then analysed and evaluated by Analysis of Variance (ANOVA) technique. SiC yield was optimized to the highest when synthesized using amorphous $\mathrm{SiO}_{2}$ with the highest-level setting for temperature $\left(1450^{\circ} \mathrm{C}\right)$, milling duration $(100$ minutes $)$, time (180 minutes) together with the minimum heating rate of $5^{\circ} \mathrm{C} / \mathrm{min}$ and only $\mathrm{SiC}$ formation was observed at $\mathrm{T} \geq 1400^{\circ} \mathrm{C}$.
\end{abstract}

\section{Introduction}

Silicon carbide ( $\mathrm{SiC}$ ) is considered a highly valued ceramic because of its properties such as high abrasiveness, corrosion resistance and high stiffness with low bulk density. The main issue faced by manufactures during the production of $\mathrm{SiC}$ materials is that there is no precise configuration of operating specification to synthesis maximum yield of SiC. Another main disadvantage of the current manufacturing method which largely focuses on the usage of furnace with extremely high temperature of about $2400^{\circ} \mathrm{C}$ and consumes about $23 \mathrm{~J} / \mathrm{kg}$ of electricity shows the inefficiency and high energy wastage during the $\mathrm{SiC}$ production [1]. This process leads to a $\mathrm{SiC}$ product with huge grain size because of the employed synthesizing method, which is the Acheson method. It also requires further milling and purification process to produce a quality component from the $\mathrm{SiC}$ precursor.

The strategy for selecting a predetermined number of examinations which creates the most data is known as partial fraction experiment [2]. Even though this technique is notable, there are no broad rules for its application or the investigation of the outcomes acquired by the tests. Dr. Genechi Taguchi built a unique arrangement of general plan rules for factorial trials that covers various engineering applications which is known as Taguchi's Method. Taguchi's method enables reduction of experiment runs while being able to investigate effects of all processing parameters. In this research, there will be four factors selected which are temperature, mechanical milling time, heating rate and time with three levels of variations for each factor which substantially reduce the number of experiment to nine times. The

\footnotetext{
*Corresponding author: mohd.aizat_g03388@utp.edu.my
} 
objective of this study is to have a clear set of operating specifications for carbothermal reduction of amorphous $\mathrm{SiO}_{2}$ by analysing $\mathrm{SiC}$ yield to study the significance of each operating specification using Taguchi's Design matrix together with Analysis of Variance (ANOVA) technique.

\section{Methodology}

The L9(34) orthogonal design matrix was selected for this research as it involved four processing parameters while running three levels for each factor and using the degree of freedom approach, nine experiments are needed to understand the effect of all four parameters. The lowest and the highest range each of operating parameters from the literatures were identified and tabulated in Table 1.

Table 1. Operation Specifications of Experiment

\begin{tabular}{|c|l|c|c|c|}
\hline Parameter & Operating Specification & Level 1 & Level 2 & Level 3 \\
\hline $\mathrm{A}(\mathrm{min})$ & $\begin{array}{l}\text { Mechanical Milling } \\
\text { Duration }\end{array}$ & 20 & 60 & 100 \\
\hline $\mathrm{B}(\mathrm{min})$ & Time & 60 & 120 & 180 \\
\hline $\mathrm{C}\left({ }^{\circ} \mathrm{C} / \mathrm{min}\right)$ & Heating Rate & 5 & 10 & 15 \\
\hline $\mathrm{D}\left({ }^{\circ} \mathrm{C}\right)$ & Temperature & 1350 & 1400 & 1450 \\
\hline
\end{tabular}

Nine sets of experiments using carbothermal reduction process were conducted according to designated setting of $\mathrm{L} 9(34)$ orthogonal design matrix involving four operating specifications. The responses in terms of $\mathrm{SiC}$ yield were recorded two times for each of the experiment.

Larger amount of $\mathrm{SiC}$ yield will be the most favourable feature, and thus, was categorized in the 'higher the better' quality characteristic. The mean square deviation (MSD) related to the 'higher the better' feature was calculated from the equation (1):

$$
M S D=\frac{\left(\frac{1}{R_{1}^{2}}+\frac{1}{R_{2}^{2}}\right)}{2}
$$

These values were then converted into their equivalent signal to noise ratios $(\mathrm{S} / \mathrm{N})$ as in equation (2):

$$
S / N=-10 \log (M S D)
$$

The four-operating specifications affect the SiC yield with contrasting amplitude. Analysis of variance (ANOVA) was conducted to analyse the proportionate contribution of various operating specifications through decomposition of the total variation into appropriate components.

\section{Results and discussions}

Considering the contributing factors studied in this research as mentioned in the introduction with their respective levels chosen as portrayed in Table 2 to produce silicon carbide using carbothermal reduction method with amorphous silicon dioxide and carbon as the precursor 
material, statistical evaluation utilizing the Taguchi's Model were executed largely to forecast and anticipate the most favourable operation specification for this study. Experimental response indicated that the most noteworthy operating specification influencing the production of $\mathrm{SiC}$ was temperature in which the amorphous $\mathrm{SiO}_{2}$ and carbon mixture was burned under carbothermal reductin. It is then followed by milling duration, reaction time and heating rate being the least significant factor. From these experiments, it can be observed that Run 8 resulted with the highest SiC yield as compared with Run 5 which showed the least $\mathrm{SiC}$ yield. With these results, no conclusive statement can be made as a more detailed analysis was required to study the effects and significance of each operation specifications on $\mathrm{SiC}$ yield.

Table 2. The results based on L9(34) orthogonal design matrix

\begin{tabular}{|c|c|c|c|c|c|c|c|c|c|c|c|}
\hline \multirow[b]{2}{*}{ No. } & \multicolumn{4}{|c|}{ Factor } & \multicolumn{4}{|c|}{ Operation Specification } & \multicolumn{2}{|c|}{ SiC weight } & \multirow[b]{2}{*}{$\mathbf{S} / \mathbf{N}$} \\
\hline & $\mathbf{A}$ & $\mathbf{B}$ & $\mathbf{C}$ & D & $\begin{array}{l}\text { Milling } \\
\text { Time } \\
\text { (min) }\end{array}$ & $\begin{array}{l}\text { Time } \\
\text { (min) }\end{array}$ & $\begin{array}{l}\text { Heating } \\
\text { rate } \\
\left({ }^{\circ} \mathrm{C} / \mathrm{min}\right)\end{array}$ & $\begin{array}{c}\text { Temp. } \\
\left({ }^{\circ} \mathrm{C}\right)\end{array}$ & $\begin{array}{l}\text { R1 } \\
\text { (g) }\end{array}$ & $\begin{array}{l}\text { R2 } \\
\text { (g) }\end{array}$ & \\
\hline 1 & 1 & 1 & 1 & 1 & 20 & 60 & 5 & 1350 & 6.26 & 6.12 & 15.83 \\
\hline 2 & 1 & 2 & 2 & 2 & 20 & 120 & 10 & 1400 & 7.77 & 7.45 & 17.62 \\
\hline 3 & 1 & 3 & 3 & 3 & 20 & 180 & 15 & 1450 & 9.96 & 9.73 & 19.86 \\
\hline 4 & 2 & 1 & 2 & 3 & 60 & 60 & 10 & 1450 & 10.62 & 10.81 & 20.60 \\
\hline 5 & 2 & 2 & 3 & 1 & 60 & 120 & 15 & 1350 & 6.11 & 5.90 & 15.57 \\
\hline 6 & 2 & 3 & 1 & 2 & 60 & 180 & 5 & 1400 & 10.80 & 10.50 & 20.54 \\
\hline 7 & 3 & 1 & 3 & 2 & 100 & 60 & 15 & 1400 & 8.78 & 8.77 & 18.86 \\
\hline 8 & 3 & 2 & 1 & 3 & 100 & 120 & 5 & 1450 & 12.16 & 12.36 & 21.77 \\
\hline 9 & 3 & 3 & 2 & 1 & 100 & 180 & 10 & 1350 & 9.50 & 9.44 & 19.53 \\
\hline
\end{tabular}

As part of Taguchi's optimization technique, mean effects of each operating specification for respective levels were calculated and plotted on the graph as shown in Figure 1(a)-(d). From these data, it can be observed that there is a steady escalation for the effects from the first to the third level of the three-operating specifications: mechanical milling duration, time and temperature. From these graphs, it can be analysed that the $\mathrm{SiC}$ response rate will stepup if these three-operating specifications are levelled up. On the contrary, when the heating rate is increased, $\mathrm{SiC}$ yield of the resultant reaction decreases.

Based on the first parameter that was studied in this research which was mechanical milling duration, it can be seen from Fig 1(a) that the SiC yield increases as mechanical milling rate increases from level setting of 20 minutes to 100 minutes [3]. This means that, the random degree of disorder for the precursor amorphous structure of silicon dioxide sand still increases after mechanical milling. The second parameter that was studied to be optimized was the time of carbothermal reduction process. As portrayed in Fig. 1(b), as the time increases from 60 to 180 minutes, the $\mathrm{SiC}$ yield also increases. This phenomenon was explained by Seo et. al [4] whereby the increase in reaction rate increases the $\mathrm{SiC}$ whiskers thickness. It can also be explained that for reaction time that is longer than 120 minutes, the generation of $\mathrm{SiO}$ gas is more homogenous; thus, promoting the reduction process which leads to thick whiskers formation and a higher SiC yield with low aspect ratio [5].

Contrarily with the rest of the operating specifications studied, heating rate had a negative effect for the SiC yield as portrayed in Fig. 1(c). This finding can be co-related with past literature analysis which stated that the increase in heating rate reduces the surface area for reaction to take place, which in turn, reduces the $\mathrm{SiC}$ formation [6]. High heating rate will be able to transfer more heat for the reaction but it will reduce the time feasible for the reactant to react. As the transport of reactants and chemical reaction being time-dependent 
phenomena, inadequacy of time is thus expected to hinder the transformation of amorphous $\mathrm{SiO}_{2}$ to $\mathrm{SiC}$ [7]. It was found that the increase in temperature increases the $\mathrm{SiC}$ yield which can be seen in Figure 1(d). This temperature factor can be explained from the thermodynamics point of view which prefers $\mathrm{SiC}$ formation starting at critical temperature of $1350{ }^{\circ} \mathrm{C}$. This temperature effect on $\mathrm{SiC}$ yield is in accord with $\mathrm{Chen}$ et al. [8] who showed similar low $\mathrm{SiC}$ formation at temperature of below $1400{ }^{\circ} \mathrm{C}$.

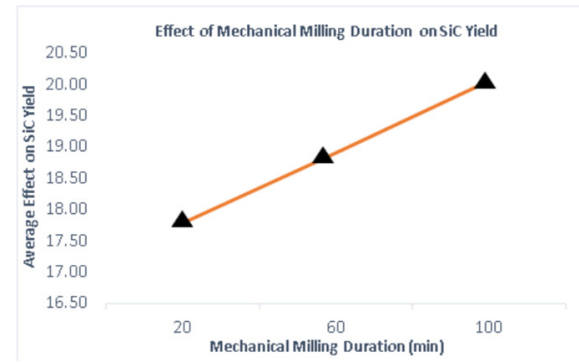

(a)

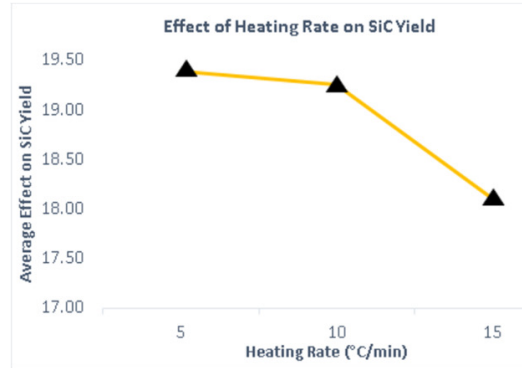

(c)

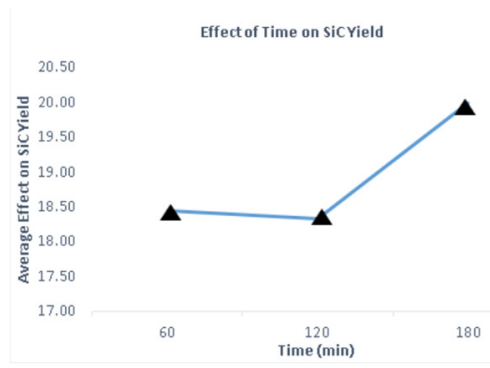

(b)

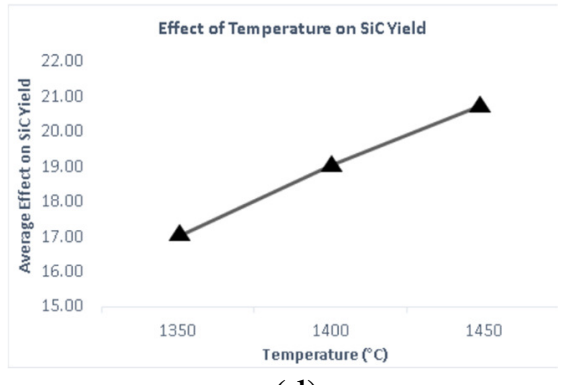

(d)

Fig. 1. Effect of each operating parameters on $\mathrm{SiC}$ yield (a) milling duration (b) time (c) heating rate and (d) temperature

\subsection{Analysis of variance (ANOVA) technique}

Analysis based on the "Percent" column as of Table 3 showed the operating specification of temperature as the highest contributing percentage $(57.229 \%)$, followed by mechanical milling duration $(20.931 \%)$, time $(13.820 \%)$ and heating rate $(8.0200 \%)$. The heating rate parameter was observed as the least significant specification towards the response data because of its low effect which can be seen to be lower than $10 \%$. Hence, it was treated as an inconsequential parameter to $\mathrm{SiC}$ formation and is thus termed together with the error value. Pooling, as described by Ibrahim et al. [9], is the process of ignoring the contribution of a selected factor and subsequently adjusting the contribution of the other factors. Hence, the new ANOVA results after pooling are as tabulated in Table 4. 
Table 3. Analysis of variance (ANOVA)

\begin{tabular}{|c|c|c|c|c|c|c|}
\hline No. & Operating Specification & DOF & $\begin{array}{c}\text { Sum of } \\
\text { Squares }\end{array}$ & Variance & F & Percent (\%) \\
\hline 1 & $\begin{array}{c}\text { Mechanical Milling } \\
\text { Duration }\end{array}$ & 2 & 7.807 & 3.904 & & 20.931 \\
\hline 2 & Time & 2 & 5.155 & 2.577 & & 13.820 \\
\hline 3 & Heating Rate & 2 & 2.991 & 1.496 & & 8.0200 \\
\hline 4 & Temperature & 2 & 21.346 & 10.673 & & 57.229 \\
\hline \multicolumn{2}{|c|}{$\begin{array}{c}\text { All other/ Errors } \\
\text { Total }\end{array}$} & 0 & - & - & & - \\
\cline { 2 - 4 } & 8 & 37.300 & & & $\mathbf{1 0 0 . 0 0 0}$ \\
\hline
\end{tabular}

Table 4. Pooled ANOVA Table

\begin{tabular}{|c|c|c|c|c|c|c|}
\hline No. & Factors & DOF & Sum of squares & Variance & F & Percent (\%) \\
\hline 1 & $\begin{array}{c}\text { Mechanical } \\
\text { Milling } \\
\text { Duration }\end{array}$ & 2 & 7.807 & 3.904 & 2.610 & 12.911 \\
\hline 2 & Time & 2 & 5.155 & 2.577 & 1.723 & 5.799 \\
\hline 3 & Heating Rate & $\{2\}$ & 2.991 & - & & \\
\hline 4 & Temperature & 2 & 21.346 & 10.673 & 7.136 & 49.209 \\
\hline \multicolumn{2}{|c|}{$\begin{array}{c}\text { All other/Errors } \\
\text { Total }\end{array}$} & 2 & 2.991 & 1.496 & & 32.081 \\
\cline { 2 - 7 } & 8 & 37.300 & & & $\mathbf{1 0 0 . 0 0 0}$ \\
\hline
\end{tabular}

After conducting the analysis with heating rate being termed together with the error value, the percentage for each operating specification reduced marginally, without changing the ranking sequence of the rest of the operating specifications. The mean impact of the fouroperating specification as shown in Table 5 gives a clear indication that the best combination to achieve maximum $\mathrm{SiC}$ yield would be when the third level of temperature, milling duration and time are selected. As shown in Table 5, for best $\mathrm{SiC}$ yield, the approximated enhancement is 4.046 against the existing mean achievement of 18.910. Based on these results, the highest $\mathrm{SiC}$ yield could be attained at the combination setting of $\mathrm{A} 3, \mathrm{~B} 3, \mathrm{C} 1$ and D3, i.e. mechanical milling duration of $100 \mathrm{~min}$, carbothermal reduction time of $180 \mathrm{~min}$, processing heating rate of $5^{\circ} \mathrm{C} / \mathrm{min}^{-1}$ and temperature of $1450{ }^{\circ} \mathrm{C}$. This combination of settings was not used in the experiments. Hence, the orthogonal array can be used to identify optimum factors in a multidimensional factor space.

Table 5. Contribution of each factors

\begin{tabular}{|l|c|c|c|}
\hline Operation Specification & Level Setting & Level & Attribution \\
\hline $\begin{array}{l}\text { Mechanical Milling } \\
\text { Duration }\end{array}$ & $100 \mathrm{~min}$ & 3 & 1.144 \\
\hline Time & $180 \mathrm{~min}$ & 3 & 1.068 \\
\hline Temperature & $1450^{\circ} \mathrm{C}$ & 3 & 1.834 \\
\hline Contributions acquired from sum of all parameters & 4.0464 \\
\hline Existing performance value & 18.910 \\
\hline Predicted response with optimum conditions & 22.956 \\
\hline
\end{tabular}




\section{CONCLUSION}

Based on the three levels of setting of the four operating specifications investigated; the increase of the mechanical milling duration $(\mathrm{min})$, temperature $(\mathrm{C})$ and time $(\mathrm{min})$ to the highest-level setting respectively to 100 minutes, $1450 \mathrm{C}$ and 180 minutes lead to maximum $\mathrm{SiC}$ response. In contrast, when the heating rate $(\mathrm{C} / \mathrm{min})$ was increased to the maximum setting of $15 \mathrm{C} / \mathrm{min}, \mathrm{SiC}$ yield reduced significantly. This trend leads to the conclusive statement of milling duration, temperature and time of reaction increment having a positive impact for $\mathrm{SiC}$ enhancement whereas increased heating rate having an adverse effect on the $\mathrm{SiC}$ yield.

Finally, from the Analysis of Variance (ANOVA) statistical calculation, it exhibited that temperature $(57 \%)$ was the most significant factor for $\mathrm{SiC}$ formation; followed by milling duration $(21 \%)$, time and heating rate $(8 \%)$ which has the least significant parameter for $\mathrm{SiC}$ formation. This information acquired from this research are crucial for manufacturers as they can now target to optimize factors based on their significance to obtain an optimal SiC yield for a higher production rate in a more economical manner.

The authors acknowledge the support provided by Universiti Teknologi PETRONAS and Ministry of Higher Education (MOHE) of Malaysia through Fundamental Research Grant Scheme (FRGS) no. $0152 \mathrm{AB}-\mathrm{K} 82$.

\section{References}

1. S. Cetinkaya and S. Eroglu, J. Eur. Ceram. Soc., 31, no. 5, pp. 869-876, (2011)

2. E. Szewczak and J. Wyrzykowski, Nanostructured Materials, 12, pp. 171-174, (1999)

3. L. C. P. Ajoy Kumar Ray, S.K. Das, Mater. Lett., 57, no. January, pp. 1120-1123, (2003)

4. M. Alcala, J. Criado, and C. Real, Solid State Ionics, 141, pp. 657- 661, (2001)

5. K. Komeya and H. Inoue, Journal of Materials Science, 4, pp. 1045-1050, (1969)

6. A. W. Weimer, D. F. Carroll, D. W. Susnitzky, and D. R. Beaman, Journal of the American Ceramic Society, 82, pp. 1635-1638, (1999)

7. W. Duan, X. Yin, Q. Li, X. Liu, L. Cheng, and L. Zhang, Journal of the European Ceramic Society, 34, pp. 257-266, (2014)

8. D. Kata, J. Lis, and R. Pampuch, Solid State Ionics, 101, pp. 65-70, (1997)

9. M. Ibrahim, N. Muhamad, A. B. Sulong, K. Jamaludin, S. Ahmad, and N. Nor, International Journal of Mechanical and Materials Engineering, 5, pp. 282-289, (2010) 